\title{
Factors Affecting Female Students Motivation Related to Enrollment and Retention in Information Technology Courses
}

\author{
Meirylene Avelino, Luciana Salgado, Raquel Bravo \\ Niterói, Brazil, 24210-310 \\ \{meirylenerea, luciana,raquel\}@id.uff.br \\ and \\ Karina Mochetti \\ University of British Columbia \\ Vancouver, BC, Canada \\ mochetti@cs.ubc.ca \\ and \\ Carla Leitão \\ PUC-Rio, Departamento de Psicologia, \\ Rio de Janeiro, Brazil, 22451-900 \\ cfleitao@gmail.com
}

Universidade Federal Fluminense, Departamento de Ciência da Computação,

\begin{abstract}
The difficulty of including women in a male-dominated environment is a growing problem over time, involving many factors such as the role of women in society. In the Information Technology context, there has been a growing concern in the industry and groups are being created with the main purpose of studying this problem and trying to reverse it. This work investigated what motivated the undergraduate students in Computer Science and Information Systems of the Universidade Federal Fluminense (Niteroi, Brazil) to choose this area and how they are experiencing the first two years of college. This research was conducted with a qualitative methodology, trying to understand the main fears, difficulties or facilities they faced before (and in the process of) choosing Technology courses. Our findings can be used to develop specific activities in the context of projects created to attract more girls to technology courses and to support undergraduate students in Computer Science Department courses. The main results indicate that there is still some uncertainty about the profession and many of them have difficulties to follow the initial content of the courses.
\end{abstract}

Keywords: Engagement, Women in Technology, Gender.

\section{Introduction}

In recent years, many projects have been developed worldwide discussing the role of women in society and trying to attract girls to careers in Information Technology (IT) areas [1] 22, 3] 4]. Such examples include the Grace Hopper Celebration of Women in Computing Congress and the Association for Women in Mathematics. According to the latest report released by the Brazilian Computer Society (SBC), it is observed that in $201514.65 \%$ of the students enrolled in the Computer courses were women. In an attempt to increase the proportion of women in the area of IT, there is a concern in several universities, development institutions, civil societies, and companies in creating incentive actions that promote the increase of the 
representativeness of women in Computing.

Within this context, several Brazilian projects were created in the last decade. Many of them are partners of Meninas Digitais Program, chancelled by SBC 2]. This program aims mainly at motivating high school students to pursue a career in IT. Our study was conducted as part of a research and extension initiative, called include $<$ meninas.uff $>$ Project [5, ,6]. Include Meninas and many other projects (Digital Girls, Tech Ladies, Maria Bit, Divas, Meninas Digitais: Regional Sul, Meninas Digitais: Regional Mato Grosso, Emilias, Cunhatã Digital, for instance) are partners of the Meninas Digitais Program.

In Computer Science Department (DCC) of Universidade Federal Fluminense (UFF), where this research was developed, the Include Meninas was designed to attract more girls to technology courses and to support undergraduate students. The DCC was founded in the 1970s and in 1985 has started the Bachelor of Computer Science course. In 1998, the Institute of Computing (IC) was created in the Technological Center of UFF as the result of the development of the activities of teaching, research and extension performed at UFF in the Computing area. The Institute is responsible for undergraduate courses in Computer Science (CS), Information Systems (IS) and Technology in Computer Systems (TCS), an e-learning modality. However, enrollment and dropout rates for girls in that courses decrease and grow, respectively, each year.

According to the data publicly provided by the university, [7] it is possible to observe disparity on the number of men and women in the courses of CS and IS. The CC course has only 66 women out of a total of 640 students while the IS course features 86 women out of a total of 569 students enrolled in the course. That is, they are $10.31 \%$ and $15.11 \%$ in the CC and SI courses, respectively. As for the number of students who entered the courses, those who canceled and those who graduated, the rates of cancellations are much higher than the graduation rates. As for the dropout rate, for example, the $\mathrm{CC}$ course presents higher numbers for female students.

Social interest and the research about the lack of interest of girls in technological areas has grown over time. Holanda co-authors $[8$, for example, applied a questionnaire between the years 2011 and 2014 during the National Science and Technology Week (SNCT). From the data collected, they found that interest in computing tends to vary depending on the school level. The performance of activities aimed at stimulating interest in computing tends to generate more productive effects in elementary school students than in high school. It is due to the fact that girls in high school already made a decision on which area to follow and that family support is of great importance for choosing a degree course.

The reasons why girls are not enrolling in Information Technology Courses need to be investigated. This work, thus, aims at investigating the motivational factors that lead the girls to enroll to the courses of CS and IS of UFF and their first perceptions after they complete the first two years in the University. We followed a qualitative and exploratory methodology [9] composed by interviews with students who entered to the DCC between 2016 and 2017. The results of our analysis indicate that the students have many doubts when choosing the career, and that can be a deciding factor in choosing to pursue a course.

This paper is organized in five sections, including the introduction. In Section 2, we present related work touching on how to increase the representativeness of women in Computing. In Section 3, we briefly describe include $<$ meninas.uff $>$ Project and some of the activities we made with undergraduate students. In Section 4, we present the goals, methodology and findings of our study. In Section 5, we conclude the paper, summarize our contributions and share new research questions and future work.

\section{Related Work}

In our review of Latin American literature, we found out studies on the factors that influence girls' participation in technological careers. Olinto's work, for example, surveyed the sociocultural dimension involving gender differences [10]. According to the author, there are two types of obstacles to describe the problems faced by women in the career choice process: horizontal segregation and vertical segregation. The choices made by women through horizontal segregation lead them to choose and follow paths that differ from the paths chosen by men. The author argues that this type of choice includes mechanisms that make career choices markedly segmented by gender. Vertical segregation is a bit more subtle, for it leads women to choose more subordinate positions, not progressing with their choices, and to adapt to that choice due to observed processes that make them think they favor a male career. For example, a pregnant woman does not receive a promotion due to the fact that she is about to gain maternity leave, or not being chosen for a trip due to the need to be close to the children and so on.

The Organization for Economic Cooperation and Development (OECD) study on education in the organization's member countries, in turn, compares educational outcomes between men and women based on the international test of school performance [11. This instrument is a psychometric test applied in schools, individually, in three areas (reading, arithmetic and writing), focused on elementary education. After the application of the test, it was observed that the school performance of boys and girls is similar, with a slight 
difference in reading tests, where girls perform better, and boys with a slight difference in math. Also in the same study it was reported that girls tend to mention a much greater interest than boys in health service areas, while technological or engineering careers are mostly male choices, considering young people in the 15-year age group. Research like the one reported in the OCDE study confirms the need to encourage female students, who often fall into horizontal or vertical segregation.

Several works were carried out with this goal in mind in Brazil and Latin American countries. In [12, a huge analysis was carried out on the participation of women in the area of computer science, based on the Universities of Argentina. The article provides data on the growth of women holding positions of authority in universities. Other researches, however, focuses on the work carried out by projects developed locally in universities. 13. presents the results of a survey conducted between 2011 and 2014, with students in elementary school from Federal District in Brazil. They report that, in recent years, the students who enrolled in the courses of the Department of Computer Science at the University of Brasilia is less than $10 \%$. The responses of students, regardless of the question, have a large number of "Maybe" answers, which may lead us to think that it is better to start with computer activities still in elementary school to encourage them to take an interest in the area. The family approval is a very important item in choosing a college degree. For girls who considered Computer Science as a possibility of higher education, the significance of this point was clear; most girls believe that computer courses have more boys than girls. This leads to the reflection that this fact can constitute an obstacle to the choice of the formation and professional activity in the area by the girls. The issue of employment in CS, however, does not seem to be an important aspect of choice for computer courses, although around 30\% of girls (responding perhaps) have not shown any clarity about employability in the computer workforce.

The work of [14] presents a work conducted with high school girls with many activities related to computing. According to the author they aimed at creating an environment of equality for women and a collective awareness to avoid prejudice and taboos with respect to the ability of women to work in technological areas. Project activities include mini-courses and workshops, training of female teams for computer marathons and hackathons, data collection, lectures for high school and undergraduate students, and technical discussions with Information Technology (IT) professionals, among other things. The article presents the results of a research carried out with high school students in a specific event to discuss careers. The research aims to find out what attracts or keep girls away from Science, Technology, Engineering e Mathematics (STEM) and IT in general.

The Project Meninas nas Ciências [15], in turn, from the Universidade Federal do Rio Grande do Sul , Brazil, carried out several visits in schools and universities. A questionnaire was used to confirm hypotheses, to draw trends, and to understand patterns about science teaching. According to Tolentino "The key feature $(. .$.$) is to gather and analyze information from students about various factors that have influenced$ their motivation to learn about science and technology." [15]. There were 3,707 questionnaires answered over the years, and the main results pointed that over the years girls lose interest in Computing and the importance of family supporting students' choices related to enrollment.

Finally, Figueiredo [16] discusses that universities have "the responsibility to foster research on gender issues in education by providing information and support the development of solutions to the problems." The influence in the onesâ choice must come from people who have already had difficulties to get to where they are, through professionals in the field, educators or students of higher level, who have had doubts that can often be equal to the doubts of those young people who are in high school going through the process of having to choose a path.

\section{Project include $<$ meninas.uff $>$}

This project is located at UFF, which has a Computer Science course since 1985. By 2016, the course had an average of 520 students enrolled, and offered 140 openings annually with admissions twice a year. More than 3,000 students have passed through the University's Computing Institute, with only 16\% being women. This small percentage has declined greatly in recent years, as seen in other Universities around the world [17] reaching alarming figures with the enrollment of only one girl in 2008.

Figure 1 shows a graph with the percentage of girls in the last 30 years. Based on this alarming numbers, our project was created with the intent of work around this problem, motivating elementary and high school students to pursue a career in the computing field and to empower undergraduate and graduate students already included in this area. Aiming on these two main goals, several activities were carried out by our project in the last couple of years, such as talks about Computer Science to girls in High Schools; participation in other projects in the University such as the Girls on Science and UFF Women; activities with undergraduate students about the gender gap in the IT field and programming courses for elementary students. Several undergraduate female students are part of the project, giving the courses, talks and 


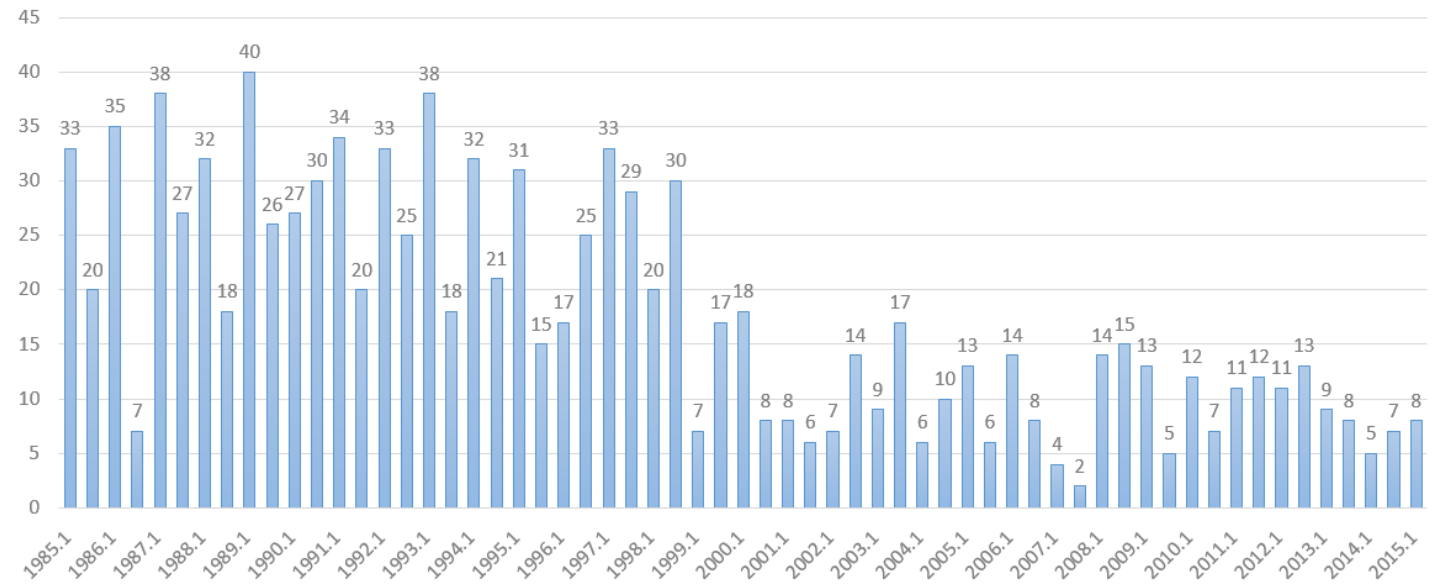

Figure 1: Graph with the percentage of female students enrolled in the Computer Science Course in the last 30 years at $\mathrm{UFF}$

publishing papers and thesis on this subject, increasing their engagement and self confidence in this male dominated world 18 19 20. For future projects, we intend to continue with the events already held, such as the Freshmen Reception, as described in the following paragraphs, and to hold programming workshops at UFF open to all high school female students. In addition, more classes for elementary school students are being planned in other schools.

Since its creation, the main activity of the project has been the Freshmen Reception. Each year, 140 new students enroll in the Computer Science course in two turns, in March (usually referred as .1) and in August (usually referred as .2) of each year. Several activities are planned by the senior students and our project is always invited for an one hour talk.

The activity is divided in three (3) main stages, each one with the purpose of analyzing and evaluating different actions and behaviors of the male and female students. Usually, five project members participated as observers: two professors and three undergraduate students, all women.

It is asked to the senior students not to inform the freshman students the main purpose of the project about the gender gap in Computer Science. Initially, the freshman participating in the activity (usually less than 40 in total, with less than 5 girls) are placed in a large circle with the intention of introducing themselves. At the end of this stage we asked some of the participants to say the name of another colleague, selected by us, researchers. It is clear that the girls draw attention to themselves, even if they do not want to. Usually all the boys already know their names and stay really quiet and pay attention when the girls are presenting themselves. The same does not happen when the boys are talking.

The second stage is a group dynamic. Students are divided into groups, with always one girl per group. This division is made by giving a number for each girl in front of everyone, then each boy receives his own number and should look for the corresponding girl. In this way we wanted the girls to have the indirect function of leadership, without it being directly imposed by us. In this dynamic, each group must unveil a hint of a treasure hunt made using the Caesar's Cipher [21.

Figure 2 shows the hint paper given to the groups. In this stage we plan to analyze how the groups would organize themselves and whether the girls would maintain (or not) the leadership position. During this stage it is possible to see boys quickly taking control of the group, not letting the girl talk or even taking the hint paper out of her hands. In some few cases the girl fights back, leading the group to victory, but it is always a struggle for the girl to be heard. The third and final stage is an open discussion with the students about the reasons for the lack of women in the field of ââIT. A debate is open as to why this number is so low and the girls had the opportunity to share personal stories about their decision to attend a male-dominated course. During this activity it is possible to observe that the boys and the girls have not yet reflected on these questions. Many boys report that they think girls are more inclined for human and biological fields, which some girls instantly denied. It is possible to hear several evidences of the obstacles faced by girls in STEM field that make them wonder whether they really want to follow this field.

\section{Empirical Study}

The empirical study consisted of conducting interviews with female undergraduate students of Computer Science and Information Systems at UFF. We aim at collecting their perceptions and understanding the 


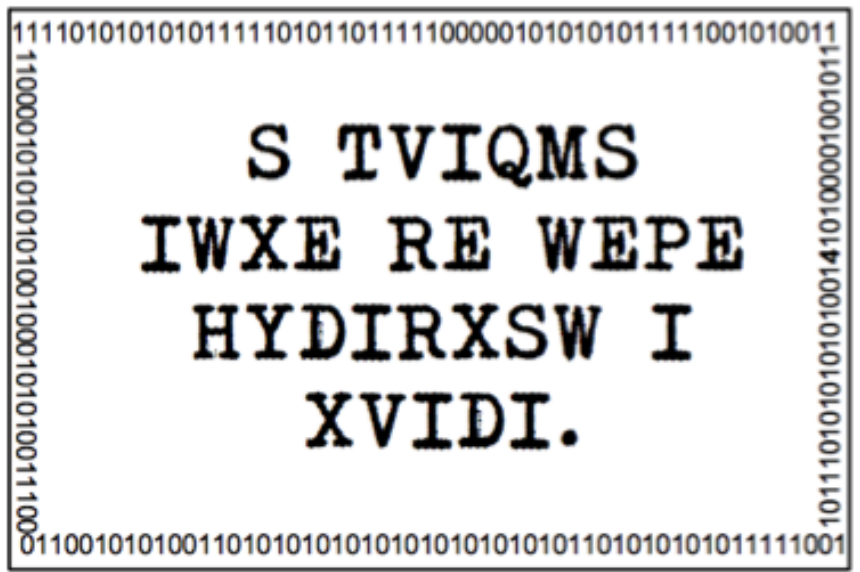

Figure 2: Caesar's Cipher for $k=4$ leading to the sentence "The Treasure is at room Two Hundred and Thirteen." ("O PREMIO ESTA NA SALA DUZENTOS E TREZE" in portuguese)

challenges we face to motivate their enrollment and retention in Information Technology Courses. Throughout this section the whole process of preparation, data collection and analysis for the interviews and the method of analysis of speech adopted (MEDS Method) 21 will be presented.

\subsection{Methodology and Procedures}

For the interviews, a qualitative method was used for exploratory research, which prioritizes an explicit analysis of the domain to be studied [22]. As in other qualitative methods that use interviews as a tool [23], it aims at listening in detail, in natural contexts and in the freest form possible, respondents have to say. The option for this method was the explicit record of the role that the discourse plays, and because, unlike other qualitative methodologies that start from previously established categories of analysis, in that case the categories emerge from the interviewees' discourses, through the observation of recurrences among their testimonials 22. MEDS Method defines steps to facilitate the process of collecting and analysing the data obtained through interviews. It is composed of 7 basic steps:

1. Outlining the main goal;

2. Recruiting participants;

3. Preparing for the data collection;

4. Collecting the data;

5. Preparing for data analysis;

6. Analysing the data;

7. Interpreting the results.

Outlining the main goal: First, it was defined as part of this scope that the participants would be girls newly enrolled in IT courses at UFF in the years 2016 and 2017, with an age group of up to 25 years. The questions were previously formulated and the main goal should always stay in mind during each interview, avoiding to deviate from the original path, which can ultimately influence the work and hinder the later data analysis. For this work two research questions were formulated:

1. Research Question 1 (Q1): What are the motivational factors for entering in an IT course?

2. Research Question 2 (Q2): What are the first impressions of the course?

Recruiting participants: The profile focused of this work is of female students enrolled in the courses Computer Science and Information Systems since the years 2016 or 2017 at UFF. First, a list with the contacts of such girls were asked to each course coordinator. A total of 27 (twenty seven) contacts of incoming female students were obtained. The invitations were then sent by e-mail. Seven girls expressed interest in participate in the interviews process out of the 27 contacted. One of the girls, for being enrolled in the project, was used as the pilot interview. In this step we had the opportunity to evaluate whether our 
research questions and script were appropriate. From the six remaining students, four were enrolled in the Computer Science Course and two were enrolled in the Information System Course. The date and time for the interview were scheduled by e-mail and by mobile messages individually. In this work we refer to each participant as P1, P2, P3, P4, P5 and P6.

Preparing for the data collection: In this step we defined the format of the interviews, the location in which they would take place and the instrument used to collect data. According to the MEDS Method, the discourses need to be collected in the most natural environment possible to make the interviewee comfortable in expressing their opinions, criticism and fears. At this stage, a semi-structured interview script was developed and a pilot interview was conducted to "calibrate" some questions, establishing if it was necessary to make any adjustments to the script, equipment or any other detail involved. A consent form was elaborated for all the interviewees to acknowledge and the interview was only carried after the proper consent.

Collecting the data: Six interviews were conducted in our research. One of the guidelines of the MEDS is to listen to the interviewee as depth as possible and let the interviewee feel free to talk openly about the subject. Due to schedules conflicts, some interviews were carried out by Skype, but still followed the same accuracy stated by the consent form, such as duration of the interview, equipments used to record and so on. The location of the in-person interviews was the dependencies of the Institute of Computing at UFF, the university attended by all interviewees. Each interview took about 30 minutes on average. The researcher collected the consent form for the in-person interviews, and sent the consent form by email for the Skype interviews. The audio of each interview, which represents the main empirical evidence of this research, was recorded digitally.

Results Interpretation: All the interviews were duly registered by the transcription of the speeches done into a text file to begin the analysis. In conducting the first round of intra-participant analysis, responses from all six participants were analyzed separately. During this activity, the first categories of meanings were cataloged. Then, the inter-participant analysis was started in which all responses were analyzed together. At the end of this stage, changes in category mapping were noted. Some categories were excluded, others consolidated or had their description adjusted. In subsequent rounds, inter-participant and intra-participant analysis were performed again, cyclically, with the goal of refining the list of categories of meanings. The knowledge acquired during this stage allowed the researcher to broaden his point of view of the analysis of the interviewees' discourse, producing relevant adjustments in the list of categories.

\subsection{Categories of meanings}

The analysis produced a document with more than 50 excerpts extracted from the interviews. The following categories of meanings were identified for the first research question (Q1) about what are the motivational factors for entering in an IT course: motivation and incentives for admission to university (C1); reactions from family and friends regarding the course choice $(\mathrm{C} 2)$; previous participation in technical courses, events, or any other information about the IT field (C3); information on the gender gap issue in the academic and corporate environments (C4).

Regarding the second research question (Q2)about the first impressions of the course, the main categories of meaning were: general first impressions on the chosen course concerning people and/or subjects (C5); difficulties related to the subjects of the first semester (C6); suggestions about activities and/or improvements that you would like to implement at the University to motivate girls into pursuing a career in the IT area (C7); the Project include $<$ meninas.uff $>$ was considered positive during the initial years of the students (C8).

\subsection{What Are The Motivational Factors For Entering In An IT Course? (Q1)}

One of the most recurrent factors for choosing a computer-related course was the family incentive (Q1, C1), see Table 1. This motivation occurred in different ways such as identification of the participant profile with the area; inspiring example of relatives already engaged in the field and gifts that resembled the IT area, among others.

Table 1: C1 - Motivation and incentives for admission to university

\begin{tabular}{ccccccc} 
& P1 & P2 & P3 & P4 & P5 & P6 \\
\hline Examples of Relatives & $\mathrm{X}$ & & & $\mathrm{X}$ & & \\
\hline Gifts that whetted & & & & \\
curiosity in technology & & $\mathrm{X}$ & & \\
\hline $\begin{array}{c}\text { Perception of } \\
\text { attitudes to pursue a } \\
\text { career in technology }\end{array}$ & & & & \\
\hline
\end{tabular}


Following, we can cite some reactions from family and friends regarding the choice of course (Q1, C2). It is possible to note that even though some reactions are positive, others have characteristics that, in a way, may discourage girls' choice. For example, participants P3 and P5 reported that their parents were concerned about the safety, both physical and psychological, of their daughter while attending the course. They had been afraid of their daughter to suffer some kind of physical or moral harassment. Participant P2 reported that to have little knowledge about IT courses is common fact among young people and their families: "My mother and my father were not surprised, but my grandmother and grandfather have not yet fully understood what I do." (Q1, C2)

Table 2: C2 - Reactions from family and friends regarding the course choice

\begin{tabular}{ccccccc} 
& P1 & P2 & P3 & P4 & P5 & P6 \\
\hline $\begin{array}{c}\text { Concern about physical } \\
\text { psychological safety }\end{array}$ & & & & & & \\
\hline Unawareness of IT area & & & & & & \\
\hline Discouragement & $\mathrm{X}$ & & & & \\
\hline
\end{tabular}

The previous participation in technical courses, events, or other activities related to computer (Q1, C3) is also a strong source of decision for choosing IT field, as P1 reveals. P1: "That's why I chose computing. Due to an IT course (...). I attended an event during high school. I even did a keynote speech at the Bradesco Foundation, about an nutrition algorithm that we created, about obesity (...)". (Q1, C3)

The interest in games and little interest in humanities area sharpened the interest of the participant P5 and made her realise a predisposition for the technological area. P5: "So, I was kind of lost in high school, but I realized that what I liked had to do with computers, with games and then one day I realised: Computer Science! (...) And I did not have second doubts because I was never very into the humanity field . I've always been from the STEM field. So for me, Computer Science fits that profile." (Q1, C3)

Table 3: C3 Previous participation in technical courses, events, or any other information about the IT field $\begin{array}{llllll}\mathrm{P} 1 & \mathrm{P} 2 & \mathrm{P} 3 & \mathrm{P} 4 & \mathrm{P} 5 & \mathrm{P} 6\end{array}$

\begin{tabular}{ccccc}
\hline $\begin{array}{c}\text { Technical secondary } \\
\text { education or courses }\end{array}$ & $\mathrm{X}$ & & & \\
\hline Play activities & & & & \\
\hline Search for self & & & $\mathrm{X}$ & \\
\hline
\end{tabular}

The gender gap in academic and corporate environments (Q1, C4) is a recurring fact during the interviews. Almost all reports had some relation with this particular subject. Many participants are already used to hear comments about their course being a male dominant field and they seem to have a certain conformity with this fact. P1: "You say you do something with computing and people already look a bit crooked at you. But I see no difference. (...) I'm already used to it because in the high school out of 30 people there were only 4 girls counting myself so I'm already used to it." (Q1, C4)

It is possible to notice some dissatisfaction about the comment heard by the girls, and some discontentment with the way society sees IT nowadays. Some participants demonstrated interest in classes attended only by girls, and taught only by female professors.

P2: "It is not because man sees the world in a better way nor because the woman sees the world in a better way. Everyone treats as if men are only about reason and women are only about emotion. But I am proof that it ain't so, I am rational. (...) The positive aspect of us girls joining this area is that we are able to bring more of our vision here, to bring a bit of the feminine world, and also to solve our own needs as a woman with the technology. We can do both."

Analysing these evidences, we noted that participants are conformed with the masculine majority of the field, but they show dissatisfaction with the comments they hear. Some suggests new classes taking into consideration only girls. P2: "Maybe you should create a different subject only for girls because they are not envolved in IT courses as men are. To give programming lessons just for girl in $C$, and create programming marathons just for girls... I think that would be super cool! (...) It is one of my dreams to build a programming school or something else only for girls."

\subsection{What are the first impressions of the course? (Q2)}

The first few weeks in a new course at any university course are indeed a unique experience for any student. It could be a roller coaster of feelings like joy, fear, anxiety. However, participants P1 and P5 presented positive points that they experienced in the first weeks of the new course concerning the reception of senior 
Table 4: C4 Information on the gender gap issue in the academic and corporate environments

\begin{tabular}{ccccccc} 
& $\mathrm{P} 1$ & $\mathrm{P} 2$ & $\mathrm{P} 3$ & $\mathrm{P} 4$ & $\mathrm{P} 5$ & $\mathrm{P} 6$ \\
\hline Acceptance of the fact & $\mathrm{X}$ & $\mathrm{X}$ & $\mathrm{X}$ & & $\mathrm{X}$ & $\mathrm{X}$ \\
\hline Dissatisfaction with the topic & $\mathrm{X}$ & $\mathrm{X}$ & & & $\mathrm{X}$ & \\
\hline $\begin{array}{c}\text { Suggested classes only with } \\
\text { girls }\end{array}$ & & $\mathrm{X}$ & & & \\
\hline
\end{tabular}

studentsv(Q2, C5). P1: "I quite liked it. They were very receptive (...) the games, the reception (...) I think the subjects cover in the first period are correct as a first contact. It's all right!" (Q2, C5) P5: "I felt very welcomed. Although the professors are mostly very strict, they were not too severe." (Q2, C5)

Table 5: C5 - General first impressions on the chosen course concerning people and/or subjects.

\begin{tabular}{ccccccc} 
& P1 & P2 & P3 & P4 & P5 & P6 \\
\hline Good Reception & $\mathrm{X}$ & & & & & X \\
\hline $\begin{array}{c}\text { Note some difficulties } \\
\text { with other people } 2\end{array}$ & & & \multicolumn{3}{c}{ X } \\
\hline
\end{tabular}

The first semester at the university can be very challenging for the newcomers. Whether because there are deficiencies in basic education or because most of the course subjects are totally new to the students. Due to these and other factors, difficulties with grades and attendance may arise. (Q2, C6). Some participants revealed the difficulties experienced in those subjects. P1: "I have some problems with Calculus and Geometry. I'm still adapting to the university pace that is quite different."(Q2, C6) P6: "I've never had a previously contact with computing. (...) I did not know how to properly study. Because we do all the exams by hand on paper and I was used to study programming using the application, you know? So when we had an exam, I made several mistakes and I could not fix them."(Q2, C6)

Table 6: C6 Difficulties related to the subjects of the first semester.

\begin{tabular}{ccccccc} 
& P1 & P2 & P3 & P4 & P5 & P6 \\
\hline Difficulties experienced & $\mathrm{X}$ & & $\mathrm{X}$ & $\mathrm{X}$ & $\mathrm{X}$ \\
\hline Some difficulties with other people & & & & & & $\mathrm{X}$ \\
\hline
\end{tabular}

Participants also made some suggestions about activities and/or improvements that they would like to implement at the university to motivate girls into pursuing a career in the IT area (Q2, C7). P2: "To make dynamic and interactive activities (...) I do not see any kind of deficiency in relation to the activities here. Because I notice that the girls are very fulfilled in here." (Q2, C7)

Table 7: C7 - Suggestions about activities and/or improvements that you would like to implement at the University to motivate girls into pursuing a career in the IT area

\begin{tabular}{ccccccc} 
& P1 & P2 & P3 & P4 & P5 & P6 \\
\hline $\begin{array}{c}\text { Activities and/or } \\
\text { improvements to UFF }\end{array}$ & $\mathrm{X}$ & $\mathrm{X}$ & $\mathrm{X}$ & $\mathrm{X}$ & & \\
\hline
\end{tabular}

Finally we identify in the interviews a positive reaction and a good receptivity of the female students in concern with the Activity with Freshman Students organized by our project, described at Section 3.1 (Q2, C8).

P2: "I was at one of the talks, but I don't know if I was at all the activities. I liked it a lot and I felt very welcomed by people who sees the world in the same way that I do, trying to make this world of technology more female. (...) There was an activity in the auditorium that gave us space to talk and I was the only girl to speak and I do not believe that this happen because of some pressure." P2: "Learn to code has changed my life. It has opened my eyes and see the world in a general way. Because to do a program we have to think to ourselves 'what if that happens?'. This is something that has changed my life and I hope it changes the lives of many girls too."

The analysis of the interviews generated some hints that can aid to disclose the reasons behind the gender gap on technological areas. The most recurring points reported by practically all the interviewees were the subcategories C4 (Information on the gender gap issue in the academic and corporate environments), which answers the first research question (What are the motivational factors for entering in an IT course). The category of meanings C7 (Suggestions about activities and/or improvements that you would like to implement 
Table 8: C8 - The Project include $<$ meninas.uff $>$ was considered positive during the initial years of the students

\begin{tabular}{lcccccc} 
& $\mathrm{P} 1$ & $\mathrm{P} 2$ & $\mathrm{P} 3$ & $\mathrm{P} 4$ & $\mathrm{P} 5$ & $\mathrm{P} 6$ \\
\hline Strengths issues & & $\mathrm{X}$ & $\mathrm{X}$ & $\mathrm{X}$ & $\mathrm{X}$ & \\
\hline
\end{tabular}

at the University to motivate girls into pursuing a career in the IT area) and C6 (Difficulties related to the subjects of the first semester) that answers the second research question 2 (What are the first impressions of the course?) refer to a certain degree of conformity of the girls in relation to the difference in the number of male students found in the courses, some difficulties encountered in the first weeks at the university, and suggestions for activities and/or improvements. The other subcategories are cited in the speeches collected in a lesser degree of recurrence, which do not make them less relevant. One example can be noted in answers about self-exploration of computational subjects in category C3 that answers Research Question 1. This shows that previously learning these subjects can rather stimulate interest in technology. The receptivity of the veterans makes the freshmen feel welcomed as can be observed in subcategory C6. It was not possible to classify some factors, such as concern for physical security and difficulties encountered in initial course subjects, mainly due to being representatives of both courses, Computer Science and Information Systems.

\section{Conclusions and Final Considerations}

Our research contributions touch on how to react before the period they have to choose a career and with the involvement of their parents and school. We highlight some contributions that, in our view, can be of interest and value for other researchers and practitioners involved in the theme. As a conclusion of our findings, we saw that the stimulus and encouragement is crucial to determining the course choice, so as the examples of parents who have already studied or worked in the field, personal attitudes that stimulate their interest in the technology area. We can also observe that the lack of information about what a professional in the area will actually do, can be pointed out as a factor that, if the student does not seek to research on her own, can cause disinterest in the area. Many girls has faced little encouragement, as can be seen in participant P1's report: "Some were very happy, and others said that I would not be able to." This discouragement often comes from one's own family, either by a comment that makes the girl feel unmotivated or some attitude that can generate negative effects. With respect the first two years in University, almost all the participants raised positive points of the activities carried out by our project, specially the activity with freshmen students. The girls liked the activity pointing some positive factors, indicating that our project is on the right track in motivating the computational interest of incoming girls and in addressing a theme that is not recurring in elementary and middle schools. Our study has analysed a specific university and geographic region, but the same kind of analysis may be done for others places. In pedagogical terms, the study also shows that the difficulties girls face with the initial disciplines (mainly with programming) are because they did not have a previously contact with computing and were not prepared to face the learn the content of the courses. Some of the schools also do not offer any kind of opportunities to support the students in this decision. Since this is an initial study, there are questions derived from its limitations to be answered by further studies. Because it was done with a single university and a small number of participants, it indicates what has happened (and can happen again), but not necessarily must happen. Therefore, we can plan future predictive (or non-predictive) research, with mixed research methods:

a) Which are the reasons for not choosing Technological Courses in other Brazilian regions?

b) Can the teaching of computational thinking and software engineering basics at school lead later to avoid difficulties in the initial years in university?

c) Will the number of female students increase if we do activities that bring them closer to Information Technology at school period?

Aiming at answering some of these question future work by some of the authors of this paper includes empirical studies in schools and the development of activities in the context of Include Project to empower our undergraduate students.

\section{Acknowledgment}

The authors want to thank PROEX (UFF) and the Brazilian funding agencies that support this project in different ways: CAPES, CNPq and FAPERJ. They would also like to express their gratitude to the volunteers who participated in the study. 


\section{References}

[1] C. Maciel, S. A. Bim, and K. da Silva Figueiredo, "Digital girls program: Disseminating computer science to girls in brazil," Proceedings of the 1st International Workshop on Gender Equality in Software Engineering, p. 29ت̈a32, 2018. [Online]. Available: https://doi.org/10.1145/3195570.3195574.

[2] F. Rodrigues, T. Conte, L. Lobo, V. Aires, and N. Dantas, "Programming contests and mobile apps development as actions for attracting and retaining brazilian women in computing courses," VIII Latin American Women in Computing Congress (VIII LAWCC), pp. 44â52, 2016.

[3] C. Maciel and S. A. Bim, "Programa meninas digitais - ações para divulgar a computação para meninas do ensino médio," In Computer on the Beach., 2016.

[4] M. Lobo, K. Ribeiro, and C. Maciel, "Mulheres negras na computação e tecnologias: Autoafirmação identitária e resistência" X LAWCC â Latin American Women in Computing Congress. Anais do CLEI,2018.

[5] K. Mochetti, L. Salgado, A. Zerbinato, B. L. Souza, and M. R. E. Avelino., "Ciência da computação também é coisa de menina," WIT at Brazilian Computer Society Congress, 2016.

[6] K. Mochetti, R. Bravo, L. Salgado, C. L. ao, C. Braga, G. Hecksher, and K. Pontes., "Discussão da posição de calouras de ciência da computação," WIT at Brazilian Computer Society Congress, 2017.

[7] UFF, "The UFF Transparencia website," 2019. [Online]. Available: https://app.uff.br/transparencia.

[8] M. Holanda, R. M. ao, G. N. Ramos, A. P. F. de Araújo, and M. E. T. Walter., "Uma pesquisa com alunas do ensino fundamental e méedio sobre os cursos da área de computação," Artigo do XXXVI Congresso da Sociedade Brasileira de Computasao, 2017.

[9] I. Seidman., "Interviewing as qualitative research: A guide for researchers in education and the social sciences," Teachers college press, 2013.

[10] G. Olinto., "A inclusão das mulheres nas carreiras de ciência e tecnologia no brasil," Artigo. Doutoranda em comunicasao e cultura., 2013. [Online]. Available: http://revista.ibict.br/inclusao/article/view/1667/1873i.

[11] OECD., "Measuring gender (ine) quality: introducing gender institutions and development data base (gid): Dev/doc," 2017. [Online]. Available: hhttp://www.oecd.org/dev/36228820.pdfi.

[12] R. A. Rodríguez, M. R. Martinez, C. G. Alderete, P. M. Vera, and M. G. Dogliotti., "Análisis de la participación de la mujer en informática," LAWCC 2017, pp. 1â6, 2017.

[13] M. T. de Holanda, G. N. Ramos, R. N. Mourao, A. Araujo, and M. E. Walter, "Percepao das meninas do ensino médio sobre o curso de computa̧ao no distrito federal do brasil," LAWCC 2017, pp. 53â59,2017.

[14] F. G. Nakamura, T. Santos, R. F. Rodrigues, and T. Lauschner, "Brazilian high school girls: What drives their career choices?" LAWCC 2017, pp. 69â76, 2017.

[15] C. Brito, D. Pavani, and P. L. Jr., "Meninas na ciência: Atraindo jovens mulheres para carreiras de ciência e tecnologia," 18f. Gênero, 2016.

[16] L. C. B. Tolentino-Neto, "Os interesses e posturas de jovens alunos frente ás ciências: resultados do projeto rose aplicado no brasil," 164F. Tese de Doutorado, Universidade de Sao Paulo., 2008. [Online]. Available: http://roseproject.no/network/countries/brazil/bra-caldeira-tolentino-neto.pdf.

[17] K. Figueiredo and C. Maciel, "Reflexões sobre gêneros, tecnologia e processo vocacional," Artigo para o XXXVI Congresso da Sociedade Brasileira de Computaão, 2017.

[18] Q. Bui, "Who studies what? men, women and college majors." NPR.org. [Online]. Available: http://www.npr.org/sections/money/2014/10/28/359419934/ who-studies-what-menwomen-andcollege-majors.

[19] D. Macedo, K. Bentes, M. Ferreira, and K. Mochetti, "Uma an İálise sobre a falta de mulheres editando a wikipédia." International Wikipedia Scientific Conference (IWSC), 2017.

[20] C. Braga and K. Mochetti, "O impacto de ferramentas de aprendizagem na discrepância de gênero em computaão." In Computer on the Beach, 2017. 
[21] M. R. E. Avelino, "Projeto \#include: Um novo olhar sobre a inclusão das meninas no departamento de ciência da computação." Trabalho de Conclusão de Curso, UFF, Niterói, Brasil, 2017.

[22] G. P. L. Dennis, "Cryptology: From caesar ciphers to public-key cryptosystems," The College Mathematics Journal, vol. 18, 1987.

[23] A. M. Nicolaci-Da-Costa, C. F. Leitao, and D. Romao, "Como conhecer úsuarios atravées do método de explicitaão do discurso subjacente (meds)," VI Simp İosio Brasileiro sobre Fatores Humanos e mSistemas Computacionais, IHC, 2004. 